\title{
Jerónimo de Orozco y las reformas ovandinas en la Nueva Galicia*
}

\section{Jerónimo de Orozco and the Ovandine Reforms in Nueva Galicia}

\author{
Víctor M. GONZÁLEZ ESPARZA \\ https://orcid.org/0000-0002-4271-3880 \\ Universidad Autónoma de Aguascalientes (México) \\ victor.gonzalez@edu.uaa.mx
}

\section{Resumen}

El objetivo del presente trabajo es analizar las "reformas ovandinas" en la Nueva Galicia a partir de la presidencia y gobernación de Jerónimo de Orozco de la Audiencia de Guadalajara, con base en la correspondencia de éste y de los oidores al Consejo de Indias y al rey. Más allá de la guerra "a fuego y a sangre" del virrey Martín Enríquez, el analizar las políticas de pacificación desde la perspectiva del doctor Orozco muestra la coincidencia con las reformas de Juan de Ovando y con la política de defensa de la población indígena, como parte de la consolidación de la Monarquía castellana en Indias.

Palabras clave: reformas ovandinas; Jerónimo de Orozco; Audiencia de Guadalajara; Nueva Galicia; guerra chichimeca.

\begin{abstract}
The objective of this work is to analyze the "Ovandine reforms" in Nueva Galicia, under the presidency and government of Jerónimo de Orozco of the Audiencia of Guadalajara, based on the correspondence between the Audiencia and the Council of the Indies, and the king. Beyond the war "a fuego y a sangre" of the Viceroy Martín Enríquez, the text analyzes the pacification policies from the perspective of doctor Orozco in coincidence with the reforms of Juan de Ovando and with the policy of defense of the indigenous population, this as part of the consolidation of the Castilian Monarchy in the Indies.
\end{abstract}

Keywords: Ovandine reforms; Jerónimo de Orozco; Audiencia of Guadalajara; Nueva Galicia; Chichimeca war.

* Agradezco muy especialmente la labor de los editores de esta revista y de los lectores anónimos que me ayudaron a enriquecer este trabajo. 


\section{Introducción}

En un estudio clásico sobre el Estado y su evolución en la colonización castellana en América, Pietschmann, al cuestionar la visión patrimonialista sobre dicho Estado, lo calificó como "el organismo estatal más desarrollado de aquella época en dirección hacia el ideal racional-burocrático moderno". ${ }^{1}$ Ello representó un gran avance frente a las visiones principalmente anglosajonas sobre el Estado moderno. Años después, frente a la idea del "Estado absolutista", el mismo autor analizaría los conflictos entre los poderes locales y el poder central, hasta considerar una "federalización clandestina" o avant la lettre para describir el crecimiento de los intereses oligárquicos a nivel local. Un cambio ocurría en la historiografía que el mismo autor representaba. ${ }^{2}$

Como bien lo comentó A. M. Hespanha, la historiografía político-institucional, dada la crisis contemporánea del Estado, comenzó a restaurar el pluralismo político en el sentido de analizar y recuperar diversas voces sobre todo en el Antiguo Régimen, en donde coexistían diferentes centros autónomos de poder, así como una pluralidad de jurisdicciones y derechos. " "A partir de aquí, continúa Hespanha, la autonomía de los cuerpos (familia, comunidades, Iglesia, corporaciones), las limitaciones del poder de la Corona por los derechos particulares establecidos, la arquitectura antagónica del orden jurídico, la dependencia del derecho respecto de la religión y la moral, son perfectamente comprensibles." ${ }^{4}$ Ello abrió nuevas perspectivas de investigación a partir sobre todo del estudio de actores e instituciones provinciales y locales, en interacción con las instituciones de la Monarquía castellana. De esta manera, la historiografía ha pasado de un "paradigma estatalista" a otro, en donde el orden jurídico del Antiguo Régimen posee características propias tales como la preeminencia de la religión y el pluralismo. ${ }^{5}$

${ }^{1}$ Horst Pietschmann, El Estado y su evolución al principio de la colonización española de América (México: Fondo de Cultura Económica, 1989), 162.

${ }^{2}$ Horst Pietschmann, “Actores locales y poder central. La herencia colonial y el caso de México", Relaciones, v. xIx, n. 73 (1998): 52-83.

${ }^{3}$ Antonio Manuel Hespanha, "Una nueva historia política e institucional”, Revista Mexicana de Ciencias Políticas y Sociales, v. 41, n. 166 (1996): 9-45.

${ }^{4}$ Hespanha, "Una nueva historia", 22-23.

${ }^{5}$ El concepto de "Monarquía compuesta" también tiene que ver con este reconocimiento de la pluralidad de actores e instituciones en el ejercicio del poder, véase John H. Elliott, "Una Europa de monarquías compuestas", en España, Europa y el mundo de ultramar (1500- 
Hay otra consideración importante en términos de cómo comprender el discurso y la política de protección y defensa de las comunidades indígenas dentro de esta construcción de la Monarquía compuesta castellana. Y ello tiene que ver con la consolidación de este Estado frente a las fuerzas que sostuvieron en una primera etapa la conquista y la colonización. En otras palabras, habría que pensar en las reformas que incorporaron la defensa de los derechos de los indígenas como una manera de frenar las ambiciones y los intereses de conquistadores y encomenderos, y por lo tanto como parte central de este proceso de construcción del orden político en Iberoamérica, cuestión que también lo caracterizaría frente a otros imperialismos. ${ }^{6}$

Por otra parte, la historiografía sobre las "reformas ovandinas" ha resaltado el papel del virrey Martín Enríquez de Almansa en la consolidación institucional de la Nueva España ante la crisis indiana, particularmente la guerra ofensiva contra los indios llamados chichimecas. ${ }^{7}$ Es decir, se ha pensado la autoridad en los "virreinatos" a partir de una jerarquía en donde el virrey es la representación de una estructura central y absoluta; sin embargo, dadas las características que hemos comentado de la pluralidad

1800) (Barcelona: Taurus Historia, 2009), 29-54. Para una reflexión en este sentido para las monarquías ibéricas, véase Óscar Mazín y José Javier Ruiz Ibáñez, eds., Las Indias Occidentales. Procesos de incorporación territorial a las monarquías ibéricas (México: El Colegio de México, 2012), en especial los textos de Marcello Carmagnani y Xavier Gil Pujol. Para una reflexión historiográfica al respecto, véase Xavier Gil Pujol, Tiempo de política. Perspectivas historiográficas sobre la Europa moderna, 1a. reimp. (Barcelona: Universitat de Barcelona, 2010). Bartolomé Yun Casalilla, "El imperio español entre la monarquía compuesta y el colonialismo mercantil”, en Historia global, historia transnacional e historia de los imperios. El Atlántico, América y Europa (siglos XVI-XVIII) (Zaragoza: Institución Fernando el Católico, 2019), 229-270; Carlos Garriga. "Orden jurídico y poder político en el Antiguo Régimen”, Istor. Revista de Historia Internacional, v. Iv, n. 16 (2004): 2-21.

${ }^{6}$ Pietschmann, El Estado y su evolución, 109.

7 Philip Wayne Powell, "Portrait of an America Viceroy, 1568-1583", The Americas, v. 14, n. 1 (1957): 1-24. Philip Wayne Powell, La guerra chichimeca (1550-1600) (México: Fondo de Cultura Económica/Lecturas Mexicanas, 1984). Antonio Francisco García-Abásolo González, "Resultados de una visita a Nueva Galicia”, Anuario de Estudios Americanos, n. 36 (1979): 3-39; Antonio F. García-Abásolo, Historia de las Américas. Tomo II. México en el siglo XVI, coord. de Luis Navarro García (Madrid: Ed. Alhambra-Longman; Sevilla: Universidad de Sevilla, 1992), 49-67; en una excelente síntesis, el autor estudia "las bases del poder regional” y, al analizar las reformas de Felipe II, se centra en la política del virrey Martín Enríquez, a quien ya le había dedicado un estudio. Carlos Sempat Assadourian, Zacatecas. Conquista y transformación de la frontera en el siglo XVI. Minas de plata, guerra y evangelización (México: El Colegio de México, 2008). 
de instancias en la toma de decisiones, es importante ver las respuestas de las Audiencias y los contextos para cada momento. ${ }^{8}$

La propuesta de este trabajo es observar este periodo crítico desde la óptica del doctor Jerónimo de Orozco, presidente (1572) y gobernador (1574) de la Audiencia de Guadalajara, y quien sería uno de los principales agentes en la transformación inicial de la guerra "a fuego y a sangre" en pacificación y poblamiento de la Nueva Galicia. Puede parecer que este cambio a final de cuentas reforzó los intereses económicos del imperialismo castellano; sin embargo, son reformas cualitativas que reorganizarían a la Monarquía compuesta de Felipe II a partir de su puesta en práctica principalmente en el reino de la Nueva Galicia, conformando así la relación entre el centro y los gobiernos provinciales y una peculiar forma de Estado, con una gran herencia en la vida política institucional de los países latinoamericanos.

En la primera parte de este trabajo haré una síntesis de las principales reformas ovandinas, es decir de las impulsadas por Juan de Ovando desde su visita y luego desde la presidencia en el Consejo de Indias (1567-1575), inspiradas en el Memorial de Luis Sánchez, así como de las ordenanzas sobre las Indias que tendrían un impacto relevante en las formas de gobierno y de procuración de justicia en la Monarquía compuesta castellana. Luego analizaré la puesta en práctica de estas reformas en el proceso de consolidación de la Audiencia de la Nueva Galicia a partir de la creación de la figura de presidente de Audiencia (1572) y de su unificación con la de gobernador del mismo reino (1574) en la figura de Jerónimo de Orozco. La base documental son las cartas de Audiencia y en especial las cartas del presidente Orozco al Consejo de Indias y al rey entre 1572 y 1580, recuperadas a través del Portal de Archivos Españoles (Pares), el cual ofrece la posibilidad de consultar la documentación digitalizada, en especial la correspondencia de las audiencias, ubicada en el Archivo General de Indias, lo que seguramente contribuirá a la investigación sobre la práctica del ejercicio del poder de la Monarquía hispana.

Las reformas ovandinas y las causas de la guerra chichimeca

La importancia de las reformas propuestas por Juan de Ovando, no sólo para la coyuntura crítica de los años sesenta del siglo XVI sino también para

\footnotetext{
${ }^{8}$ Sobre la importancia de las Audiencias en los gobiernos en Indias, véase Rafael Diego-Fernández Sotelo, "De las reales audiencias indianas", en Los caminos de la justicia en México, 1810-2010 (México: Poder Judicial de la Federación, 2010), 3-30.
} 
la vida institucional de la Monarquía compuesta castellana ha sido estudiada desde hace varios años. Conocemos, por ejemplo, la respuesta al cuestionario de Ovando por parte del oidor de la Audiencia de Nueva Galicia, el licenciado Miguel Contreras y Guevara, gracias a los trabajos de Rafael Diego-Fernández, quien además ha escrito ensayos esclarecedores sobre estas reformas y su impacto en la vida institucional de la Corona en general, y de la Audiencia de Guadalajara en particular. ${ }^{9}$ Sin embargo, la participación del presidente de la Audiencia de Guadalajara, el doctor Jerónimo de Orozco, no ha sido suficientemente estudiada.

Varios son los contextos en los que se explica el particular interés de Felipe II en nombrar a Juan de Ovando, visitador y posteriormente presidente del Consejo de Indias (1567-1575). En primer lugar, Ovando como inquisidor era parte del círculo del cardenal, inquisidor general y presidente del Consejo de Castilla, Diego de Espinosa, quien además fue confesor del rey y "el hombre de toda España de quien el rey hace más confianza y con quien más negocios trata [...] el más favorecido ministro que tiene $\mathrm{Su}$ Majestad, y por sus manos pasan todas las materias de estado, de hacienda y de justicia”. ${ }^{10}$ Debido a ello, el Memorial presentado por el bachiller Luis Sánchez al cardenal Espinosa el 26 de agosto de 1566 tuvo una gran influencia acerca de lo que ocurría en las Indias y cómo remediarlo. ${ }^{11}$

Otro contexto relevante de las reformas fue la política real de limitar el poder de los virreyes, aristócratas de viejo cuño la mayoría de ellos, restándoles atribuciones y pasándolas a los Consejos, los cuales comenzarían a desarrollarse precisamente debido a estas reformas. Tal proceso desde luego no fue nada sencillo, ya que no sólo era difícil sino imposible querer otorgarle una visión burocrática a los virreyes, cuando los titulares eran

${ }^{9}$ Rafael Diego-Fernández Sotelo, La primigenia Audiencia de la Nueva Galicia, 1548-1572 (Zamora: El Colegio de Michoacán; Guadalajara, Jalisco: Instituto Cultural Ignacio Dávila Garibi, 1994); Rafael Diego-Fernández Sotelo, "Mito y realidad en las leyes de población de Indias”, en Recopilación de leyes de los reynos de las Indias/Estudios histórico-jurídicos (México: Miguel Ángel Porrúa, 1987), 209-332; Rafael Diego-Fernández Sotelo, "El aparato de gobierno y justicia indiano a partir de las reformas ovandinas", Allpanchis, v. xxxıx, n. 71 (2008): 13-44; Rafael Diego-Fernández Sotelo, "La visita al Consejo de Indias de Juan de Ovando y la Nueva España”, Revista Chilena de Historia del Derecho, n. 22 (2010): 445-457.

${ }^{10}$ Geoffrey Parker, Felipe II. La biografía definitiva, ebook (Barcelona: Planeta, 2018), 153. Se trata de una carta del conde de Chinchón al gobernador de Milán, 12 de diciembre de 1566.

${ }^{11}$ Diego-Fernández Sotelo, "El aparato de gobierno", 19. El Memorial de Luis Sánchez es equiparado a los trabajos de Bartolomé de las Casas; por ello lo llaman el "apóstol de los indios de Popayán”, Colombia, si bien su maestro y mentor Juan del Valle es el equiparable. 
"familia" y parte del servicio al rey. ${ }^{12}$ De ahí que los nombramientos de Enríquez para la Nueva España y Toledo para el Perú, ambos cercanos al cardenal Espinosa, hayan sido parte de esa nueva visión de limitar los abusos de autoridad. También por ello habría que explicarnos la consolidación de la Audiencia de Guadalajara al nombrar un primer presidente en 1572, y posteriormente otorgarle la gobernación en términos militares a la Audiencia misma. En la Nueva España, después de acabar con la rebelión de Martín Cortés, el tema central sería la "guerra chichimeca", de ahí la importancia de otorgarle el sello real y el gobierno a la Audiencia de frontera, como veremos.

Se han reconocido en el Memorial de Luis Sánchez las premisas para iniciar las reformas en América. Sólo habría que destacar que no sólo se trata de una narración de la destrucción de las Indias, sino una serie de respuestas que tienen que ver con la información y la comunicación en la toma de decisiones. ${ }^{13}$ Ante la pregunta “¿cómo en 74 años que á que se descubrieron las Indias no se han remediado (los daños y crueldades cometidos a los indios)?", Sánchez respondía que dada la diversidad de las Indias las leyes deberían ser particulares, los que "vienen de Indias y desde allá escriben, informan mal y á su gusto [...]”, por lo que al gobernar con estas informaciones han "errado muchas veces"; que ante tantas mentiras, el Consejo "con razón no sabe a quién creer". ${ }^{14}$

Ante la pregunta entonces de por qué no se ha remediado la situación desastrosa en las Indias, el bachiller Sánchez no culpa ni al rey ni al Consejo pero sí a jueces eclesiásticos, clérigos y desde luego encomenderos y soldados, y ofrece respuestas que tienen que ver con la manera en que se lleva a cabo la toma de decisiones. Si la falta de conocimiento sobre las Indias, la mala información y el descrédito a los buenos informantes

12 Manuel Rivero Rodríguez, La edad de oro de los virreyes (Madrid: Akal, 2011), en especial cap. III: ¿¿ólo Madrid es corte?.

${ }^{13}$ Luis Sánchez, "Memorial que dio el bachiller Luis Sánchez, residente en Chillaron de Pareja, al presidente Espinosa, en Madrid á 26 de Agosto de 1566", en Colección de documentos inéditos, relativos al descubrimiento, conquista y organización de las antiguas posesiones españolas de América y Oceanía, sacados de los Archivos del reino, y muy especialmente del de las Indias, por D. Luis Torres de Mendoza. Tomo XI (Madrid: Imprenta de J. M. Pérez, 1869), 163-170. Luis Sánchez había estudiado en Salamanca, en donde conoció a su maestro y mentor Juan del Valle, con quien viajaría a Popayán, Colombia, convirtiéndose Del Valle en obispo y protector de indios.

${ }^{14}$ Sánchez, “Memorial”, 166-167. 
prevalecían, las decisiones no podían tomarse acertadamente. De ahí la relevancia de este Memorial para la Monarquía en su conjunto.

Finalmente, el bachiller Sánchez termina proponiendo, por una parte, "una grande junta, como conviene á negocio tan importante", en donde esté el rey, el Consejo de Indias, grandes teólogos, con experiencia en las Indias, y por la otra, personas venidas directamente de Indias:

y cada uno de lo que á visto y sabe de cada provincia, por sí, averigüase allí delante de tan buenos Jueces, la verdad, y harán confesar los buenos á la gente de Indias, lo que allá pasa [...]; y averiguado esto, que es lo que toca al hecho, V. S. y el Consejo determinen derecho, y den la órden, qual que convenga, y váyase a exequtar, que poco a poco se hará mucho en el servicio de Dios y en la conversión de los indios; y no haciéndose, siempre andaremos á tiento. ${ }^{15}$

Me he extendido en el Memorial del bachiller Sánchez porque no sólo se trata de una denuncia sino de una propuesta para transformar las formas del gobierno de Indias. Quizá por ello este breve Memorial ha sido visto como el detonador de las reformas ovandinas, ya que el nombramiento de Ovando como visitador del Consejo de Indias en 1567 y posteriormente como su presidente permitiría iniciar un proceso de formalización de las instituciones de la Monarquía hispana, lo que permitiría no obstante las sucesivas crisis del siglo XVII un cierto orden político. ${ }^{16}$

Tres serían las principales reformas realizadas por Ovando para mejorar la administración en Indias, y atender el propósito recomendado por el bachiller Sánchez de remediar los daños ocasionados a la población indígena:

a) La reorganización del Consejo de Indias y el nombramiento de consejeros y justicias con experiencia en Indias, evitando que los del Nuevo Mundo fueran promovidos y cambiaran de plaza en poco tiempo (antes de 1572 el promedio de la duración de los cargos oscilaba entre unos meses y tres años; hasta la muerte de Felipe II duraron entre seis y dieciséis años). ${ }^{17}$

15 Sánchez, "Memorial”, 169-170.

${ }^{16}$ Diego-Fernández Sotelo, “El aparato de gobierno”, 17-18. Garriga, “Orden jurídico y poder político en el Antiguo Régimen”.

17 Javier Barrientos Grandon, "Juan de Ovando", en Diccionario biográfico español, v. Xxxix (Madrid, España: Real Academia de la Historia, 2012), 372-378. 
b) Mejorar el conocimiento de las Indias a través de meticulosos cuestionarios (los "cuestionarios de Ovando") y del nombramiento de Juan López de Velasco como cosmógrafo y cronista real, el cual llevaría a cabo la Geografía y descripción universal de las Indias (15711574)

c) El proyecto de recopilación de leyes para las Indias, pensado en siete libros según el modelo de las Siete Partidas.

Con la muerte de Ovando en 1575, sólo llegaron a publicarse un título del libro primero, Ordenanzas de Regio Patronato (1574), y tres títulos del libro segundo, Ordenanzas del Consejo de Indias (1571), Ordenanzas de descubrimiento, nueva población y pacificación (1573), y las Ordenanzas de descripciones (1573). ${ }^{18}$ Ciertamente con las reformas ovandinas una nueva praxis política se gestaría para la Monarquía hispana, un método más sistemático pero a la vez flexible para adaptarse a los cambios venideros. ${ }^{19}$

Las Ordenanzas de Descubrimiento, Nueva Población y Pacificación son un buen ejemplo de estas reformas y sus repercusiones en Indias, al normar los nuevos descubrimientos por mar y por tierra y, entre varios temas, imponer incluso pena de muerte a los capitanes españoles que esclavizaran a los indios, y eliminar el título de "conquista" para que no se "pueda hacer fuerza ni agravio a los indios”. ${ }^{20}$ Ello comenzaría a cambiar el contexto de la llamada "guerra chichimeca".

La historiografía sobre la "guerra chichimeca" ha tenido un giro crítico en los últimos años, sobre todo a partir del cuestionamiento a las interpretaciones euro y anglocentristas, que han tenido como trasfondo la idea de la frontera como espacio de confrontación entre la civilización y la barbarie. El libro de referencia en este sentido sigue siendo el de Powell, quien llegó a definir dicha guerra como "el primer enfrentamiento completo y constante de la civilización y el salvajismo en este continente (americano)". ${ }^{21}$ El libro desde luego tiene varios méritos, pero no el de observar

${ }^{18}$ Diego-Fernández Sotelo, "El aparato de gobierno”, 37-39.

${ }^{19}$ Sylvain André, "El momento ovandino. De la empresa de saber a la fábrica de la acción", E-Spania. Reveu interdisciplinaire d'études hispaniques médievales et modernes (en línea), n. 33 (2019). Publicado el 18 junio 2019, consultado el 1 septiembre 2020, http://journals.openedition.org/e-spania/30715, DoI: https://doi.org/https://doi.org/10.4000/e-spania.30715. La autora resalta el papel de Mateo Vázquez en la sistematización del método ovandino.

${ }^{20}$ Diego-Fernández Sotelo, "Mito y realidad en las leyes de población de Indias". Al respecto pueden verse en especial los artículos 24 y 29 de las Ordenanzas.

${ }^{21}$ Powell, La guerra chichimeca. Esta obra fue publicada originalmente en inglés en 1952. 
la complejidad de los grupos llamados “chichimecas", lo cual ha sido el tema central del revisionismo.

Por otra parte, Powell atribuye el cambio de estrategia sobre la guerra al virrey Enríquez, a partir de la creación del sistema de presidios y fuertes y de una guerra ofensiva "a fuego y a sangre": "Los años de Enríquez, comentó, fueron vitales en la consideración gubernamental de la política general que debería seguirse para pacificar a los tribeños del norte”. En otras palabras, Martín Enríquez sentó los principios para una dirección coordinada para la guerra y la defensa de la frontera. ${ }^{22}$ Las juntas teológicas convocadas por el virrey Enríquez para discutir no sólo sobre la "justa guerra” sino también sobre si era justo o no esclavizar a los indios, y que formaron parte también de esta nueva estrategia en la toma de decisiones sobre la guerra, son vistas rápidamente por este autor como "confusiones y verbosidades del debate [que] seguían su camino tortuoso [...]”, y que terminarían por justificarla. ${ }^{23}$

Lo que sí estudió Powell fue la transformación de los capitanes y soldados españoles en la Nueva Galicia. Su interés por los "grandes guerreros" indígenas sólo se ve superado por el reconocimiento a los capitanes y soldados de guerra, a los jinetes fronterizos, como Miguel Caldera, que hicieron posible la colonización en el septentrión novohispano. Powell percibe bien la transición de las milicias españolas financiadas privadamente, por lo que los soldados españoles estaban interesados en mantener la esclavitud de los indios como medio de obtener ganancias, a las nombradas y financiadas por la hacienda real. "Tales capitanes (y los soldados que reclutaban), comenta, con salarios regulares establecidos fueron nombrados en número creciente desde mediados de la década de 1570 [...]". ${ }^{24}$ Aun cuando atribuye estos cambios al virrey Enríquez, como veremos más adelante, fue una transformación iniciada por el presidente de la Audiencia de Guadalajara, el doctor Orozco.

El estudio sobre las "huestes indianas", si bien ha tenido desarrollos importantes desde que fueran estudiadas por Silvio Zavala en su tesis doctoral sobre los intereses particulares en la conquista (1933) y su relación

${ }^{22}$ Powell, La guerra chichimeca, 115; Philip W. Powell, Capitán mestizo: Miguel Caldera y la frontera norteña. La pacificación de los chichimecas (1548-1597), 1a. reimp. (México: Fondo de Cultura Económica, 1997), 67.

${ }^{23}$ Powell, Capitán mestizo, 66.

${ }^{24}$ Powell, La guerra chichimeca, 128. 
con la esclavitud de los indios, poco sabemos sobre ellas en la Nueva Galicia y menos sobre su transformación a partir de las reformas ovandinas. ${ }^{25}$ En un buen balance sobre la institución militar en Indias, Marchena Fernández y Romero Cabot comentaron que hay antecedentes medievales en las huestes; sin embargo, se trató de una institución "puente" hacia instituciones militares modernas. El debate no está agotado porque las "huestes indianas" precedieron y convivieron con las milicias profesionales de la Corona en Indias; la lucha en contra de las "huestes indianas" fue uno de los principales proyectos de reforma durante el siglo XVI, sobre todo con Felipe II, por las consecuencias desastrosas de esclavizar a los indios, por lo que este sería el tema central en el debate sobre la guerra chichimeca. ${ }^{26}$

El debate específicamente sobre la guerra y la esclavitud de los indios en la Nueva Galicia forma parte de este proceso de conformación de las milicias modernas y de los límites a las acciones de los encomenderos y

25 Silvio A. Zavala, "Los intereses particulares en la conquista de la Nueva España (Estudio histórico-jurídico)" (Tesis de doctorado en Derecho, Universidad Central de Madrid, 1933); Silvio A. Zavala, Las instituciones jurídicas en la conquista de América (Madrid: Centro de Estudios Históricos, Sección Hispanoamericana, 1935). Para una revisión de la guerra chichimeca, véanse Salvador Álvarez, "Conquista y encomienda en la Nueva Galicia durante la primera mitad del siglo xvi: 'Bárbaros' y ‘civilizados' en las fronteras americanas”, Relaciones. Estudios de historia y sociedad, v. xxIx, n. 116 (2008): 135-88, y Salvador Álvarez, "La guerra chichimeca”, en Historia del Reino de la Nueva Galicia, ed. de Thomas Calvo y Aristarco Regalado Pinedo (Guadalajara, Jalisco: Universidad de Guadalajara, 2016), 165-159.

${ }^{26}$ Juan Marchena Fernández y Ramón Romero Cabot, "El origen de la hueste y de la institución militar indianas en la guerra de Granada”, en Andalucía y América en el siglo XVI. Actas de las II Jornadas de Andalucía y América (Huelva: Universidad de Santa María de la Rábida, 1982), 91-112. Antonio Espino López, "Las Indias y la tratadística militar hispana de los siglos XVI y XVII", Anuario de Estudios Americanos, v. 57, n. 1 (2000): 295-320; este autor considera que el origen de las huestes están en el Gran Capitán, en Italia. Existen algunos estudios sobre los grandes capitanes en Indias, véase Powell, Capitán mestizo; Diego Porras Muñoz, "Diego de Ibarra y la Nueva España”, Estudios de Historia Novohispana, n. 2 (1968): 48-78, y Charles Foin, "Un pacificateur du nord du Mexique: Rodrigo de Río de Losa”, Mélanges de la Casa de Velázquez, v. 14 (1978): 173-214. Sobre la revolución militar, véase Geoffrey Parker, La revolución militar. Las innovaciones militares y el apogeo de Occidente, 1500-1800 (Barcelona: Crítica, 1990), 69; Geoffrey Parker. "The Military Revolution, 15601660-A Myth?", en The Military Revolution Debate: Readings on the Military Transformation of Early Modern Europe, 2018, https://doi.org/10.4324/9780429496264. Irving Anthony Thompson, "Milicia, sociedad y Estado en la España moderna”, en La guerra en la historia, ed. de Ángel Vaca Lorenzo (Salamanca, España: Universidad de Salamanca, 1999), 115-134. Para su referencia a Hispanoamérica, véase Juan José Velásquez Arango, “Guerra, Estado y revolución militar en la América española durante los siglos XVI y XVII”, Historia y Memoria, n. 16 (2018): 23-52. 
grandes capitanes. ${ }^{27}$ De acuerdo con Carrillo Cázares, el fraile agustino Guillermo de Santa María, quien había convivido con guamares diecisiete años (1550-1566) y con guachichiles nueve años (1566-1575), argumentó que los indios chichimecas "principalmente han levantado tanta guerra" al ser esclavizados por los españoles, quitándoles a sus mujeres e hijos, así como la tierra y sus frutos de los cuales vivían, argumentos que van a coincidir con los de Jerónimo de Orozco presidente de la Audiencia de Guadalajara. La causa justa de la guerra de los españoles, por su parte, debería contar con la autorización real y dirigirse contra indios de guerra, no contra indios de paz. De ahí que los soldados y magistrados que esclavizan injustamente a los indios pacíficos, continuaba Santa María, “están en mala conciencia”, y por el contrario la respuesta violenta de los guamares y guachichiles, que en un principio no eran "dañosos", tendría causas "justas y justificadas". ${ }^{28}$

La diferencia central del fraile agustino con otros teólogos será la reflexión sobre "el modo de hacerse esta guerra", es decir el haber otorgado como única paga a los soldados españoles a los indios capturados para esclavizarlos y venderlos. Ello es el origen de los abusos, ya que por incrementar sus ganancias los soldados esclavizaban a indios de paz. Porque si bien el derecho canónico y natural reconocía la existencia de la esclavitud por derecho de guerra, ésta no podría darse entre cristianos, de ahí lo injusto de esclavizar a indios bautizados. Recordemos también que este será un argumento central en el alegato de Tenamaztle ante la Corona, desde los orígenes de la guerra en el Mixtón, y una de las principales razones para señalar que la guerra de exterminio a "fuego y a sangre" era injusta e inhumana. ${ }^{29}$

Generalmente este tipo de argumentos se ven separados de la práctica misma. Es hora sin embargo de adentrarnos en la gestión de Jerónimo de Orozco quien, como parte de las reformas ovandinas, tendrá la misma expli-

${ }^{27}$ Alberto Carrillo Cázares, El debate sobre la guerra chichimeca, 1531-1585, 2 v. (Zamora: El Colegio de Michoacán; San Luis Potosí: El Colegio de San Luis, 2000); Guillermo de Santa María, Guerra de los chichimecas (México 1570-Zirosto 1580), ed. de Alberto Carrillo Cázares, Zamora: El Colegio de Michoacán; Guadalajara, Jalisco: Universidad de Guadalajara; San Luis Potosí: El Colegio de San Luis Potosí, 1999.

${ }^{28}$ Carrillo Cázares, El debate sobre la guerra, v. I, 277-284.

${ }^{29}$ Carrillo Cázares, El debate sobre la guerra, v. I, 179, y v. II, doc. 19, 513-535. Miguel León-Portilla, Francisco Tenamaztle, primer guerrillero de América, defensor de los derechos humanos (México: Diana, 2005). Ambos textos incluyen la transcripción del principal documento de Tenamaztle y Bernal Díaz del Castillo, "Ciertas peticiones e información hechas en Valladolid, de don Francisco Tenamaztle”, AGI, Audiencia de México, leg. 205, 1 de julio de 1555. 
cación para la guerra que Guillermo de Santa María, incluso tres años antes de que el fraile diera a conocer su Memorial (1575). Como bien lo dijera el propio doctor Orozco, el conocer directamente las condiciones de guerra en la visita que realizara a las minas de Zacatecas en 1571, lo llevó a cambiar de opinión y encontrar en su gestión nuevos métodos para la pacificación.

\section{El doctor Orozco y las reformas ovandinas}

Quien advirtiera de los cambios en la Audiencia de Nueva Galicia a partir de las reformas propuestas por Juan de Ovando fue John H. Parry, en un trabajo pionero publicado originalmente en 1948 y cuya consulta sigue siendo indispensable. ${ }^{30} \mathrm{Al}$ referirse a la "Reorganización de la Audiencia", comenta fundamentalmente sobre el cuestionario enviado por Ovando en 1569 a Indias, para ser respondido por el oidor con más experiencia de cada audiencia.

Para el caso de Guadalajara correspondió al licenciado Miguel Contreras y Guevara hacer las “averiguaciones”, y en marzo de 1570 envió puntualmente su respuesta a Ovando. Esta respuesta ofrece un panorama de las reformas propuestas en la región, fundamentalmente a favor de la consolidación de la Audiencia de Guadalajara, con un presidente que integrara las funciones de justicia y de gobierno (que incluía las militares), y tres oidores, dejando de ser una Audiencia subordinada al virrey: "e pues esta Audiencia [de Guadalajara] está en medio de la tierra de guerra donde se hacen los dichos daños, mejor la podrá proveer teniéndolos presentes, que no el visorey que está a ochenta o más leguas lejos”, escribiría el licenciado Contreras. ${ }^{31}$

En 1568 el virrey Enríquez fue nombrado gobernador supremo de toda la Nueva España y Nueva Galicia, "con poder exclusivo, sujeto a la Corona, de nombrar funcionarios menores y jueces, así como de supervisar obras

${ }^{30}$ John H. Parry, La audiencia de Nueva Galicia en el siglo XVI. Estudio sobre el gobierno colonial español, ed. Rafael Diego-Fernández Sotelo (Zamora: El Colegio de Michoacán; México: Fideicomiso Teixidor, 1993).

${ }^{31}$ Diego-Fernández Sotelo, La Primigenia Audiencia, "Introducción”. La paleografía, transcripción y estudio de esta respuesta de Contreras al cuestionario de Ovando ha sido fundamental para entender estos procesos. Otros de los temas eran los jurisdiccionales sobre las provincias de Ávalos y la Nueva Vizcaya, así como las condiciones de los pueblos de indios y de los encomenderos. 
públicas y autorizar erogaciones de emergencia de las cajas reales". ${ }^{2}$ Así, hasta antes de la llegada a la presidencia del doctor Jerónimo de Orozco en 1572, la Audiencia de Guadalajara había perdido toda su autoridad administrativa y de gobernación, quedándose sólo y prácticamente con los juicios civiles. De ahí la importancia de las propuestas integradas por el oidor Contreras y Guevara para entender las reformas llevadas a cabo en la Audiencia.

Ciertamente las respuestas de Contreras no tienen mucha información de los propios pueblos de indios, salvo la mención del nombre y de cuántos indios tributarios existían; sin embargo, sí proporcionaron una excelente recomendación para transformar la Audiencia al nombrar un presidente (1572), ${ }^{33}$ y que integrara también las cuestiones administrativas y militares como gobernador (lo que ocurre desde 1573), lo cual recayó en el doctor Jerónimo de Orozco. ${ }^{34}$

De las cartas analizadas tanto de Orozco como de los oidores de la Audiencia dirigidas al rey y al Consejo de Indias, así como las respuestas como reales cédulas, encontramos un rico panorama de las diferentes problemáticas detectadas por el informe de Contreras y Guevara, además de la importancia que adquirió la Audiencia tanto en la parte de justicia como en lo administrativo y militar. Hemos comentado que generalmente se ha acentuado la participación del virrey Enríquez en la definición de la guerra ofensiva contra los chichimecas; sin embargo, analizar las cartas y memoriales del doctor Orozco ofrece una perspectiva más cercana y matizada de lo que estaba ocurriendo en Nueva Galicia en la década de los años setenta del siglo XVI, de cómo se ponían en práctica las reformas ovandinas en la Audiencia de Guadalajara, especialmente las referidas contra la esclavitud de los indígenas.

${ }^{32}$ Parry, La audiencia de Nueva Galicia, 192. Quien ha recuperado las diferentes disputas entre el virrey y la Audiencia es: Celina B. Becerra Jiménez, "En servicio del Rey y de Dios: institucionalización en el siglo xvı", en Historia del Reino de la Nueva Galicia, coords. Thomas Calvo y Aristarco Regalado Pinedo (Guadalajara : Universidad de Guadalajara, 2016), 263-315.

${ }^{33}$ Contreras y Guevara lo recomienda claramente y se propone él mismo para el cargo, aunque su muerte en 1571 lo impidió.

${ }^{34}$ Powell confunde a los hermanos Juan Bautista Orozco y Jerónimo de Orozco, y la confusión persiste en estudios recientes, como el de Francis Goicovich, "Dinámica de la confrontación hispano-indígena en el Reino de Nueva Galicia y regiones adyacentes, siglo XVI", Revista de Indias, v. LXXIX, n. 275 (2019) : 9-49. Incluso se encuentra en trabajos excelentes como el de: Carlos Sempat Assadourian, Zacatecas. Conquista y transformación de la frontera en el siglo XVI. Minas de plata, guerra y evangelización (México: El Colegio de México, 2008), 78-140. Quizá esta confusión persistente se debe a lo poco que los historiadores le hemos dedicado a los gobiernos provinciales. 
Poco conocemos de la biografía de Jerónimo de Orozco; nació en Sevilla, España, y estudió en Salamanca y en la Universidad de México, donde recibió la borla de doctor. ${ }^{35}$ Fue nombrado originalmente oidor de la Audiencia de México desde diciembre de 1557 hasta el 30 de abril de 1572, fecha en que sería nombrado presidente de la Audiencia de Guadalajara. ${ }^{36}$ El doctor Orozco había sido enviado como visitador a Zacatecas en 1571, ${ }^{37}$ debido a las constantes denuncias de fraudes en el cobro de los quintos de plata, por lo que pocos días antes de ser nombrado presidente informó de la necesidad de restablecer la justicia en dichas minas. Muy probablemente desde este encargo se perfiló como presidente de la Audiencia, sobre todo después de la muerte del oidor Contreras y Guevara en 1571.

No fue ciertamente un tratadista reconocido, pero sí un letrado de experiencia y con antigüedad en la Audiencia de la ciudad de México en un periodo especialmente crítico, lo cual encajaba en el perfil de los magistrados recomendados por Ovando. El estudio de sus cartas enviadas al Consejo de Indias y al rey son los testimonios hasta ahora descubiertos de su manera de pensar y sobre todo de llevar a la práctica las nuevas Ordenanzas, particularmente sobre la población indígena en medio de una guerra desastrosa en el septentrión novohispano.

Ya como presidente de la Audiencia, en la carta del 22 de diciembre de 1572 dirigida al rey, el doctor Orozco plantó un primer diagnóstico de la

35 Juan B. Iguíniz, Los gobernantes de Nueva Galicia. Datos y documentos para sus biografías (Guadalajara, Jalisco: Gobierno de Jalisco, 1981); presenta información útil aunque en algunos casos errónea: dice que el doctor Orozco muere en 1592, cuando sucede en diciembre de 1580 .

${ }^{36}$ Portal de Archivos Españoles (Pares): "Nombramiento del licenciado [Jerónimo de] Orozco como oidor de la Audiencia de México”, Archivo General de Indias (en adelante AGI), Contratación, 5787, n. 1, 1. 4, f. 179-180, del 29 de diciembre de 1557; y "Nombramiento de Jerónimo de Orozco como presidente de la Audiencia de Guadalajara", 30 de abril de 1572, AGI, Guadalajara, 230, 1. 1, f. 254r-255r; también le otorgaron licencia para llevar esclavos armados a Guadalajara, para su defensa y ejecución de justicia: "Licencia para llevar esclavos armados al doctor Orozco”, 26 de mayo de 1572, AGI, Guadalajara, 230, 1. 1, f. 252r-252v. Como lo he comentado en el texto, la consulta de las Cartas de Audiencia se llevó a cabo en Pares, durante el año 2020: http://pares.mcu.es/ParesBusquedas20/catalogo/find?nm=\&texto $=$ cartas + de + audiencia + guadalajara .

37 "Carta del doctor [Jerónimo de] Orozco, presidente de la Audiencia de Guadalajara", 14 de abril de 1572, AGI, Guadalajara, 5, r. 14, n. 27, en donde comenta las misiones que realizó en Zacatecas por motivo de los fraudes al quinto real, así como sus recomendaciones, particularmente, de quitarles la merced a los mineros de pagar el diezmo y que se les cobre el quinto real; al final insinúa la posibilidad de quedarse en el Reino de Nueva Galicia para mejor servir a vuestra majestad. 
situación en el reino, muy similar por cierto al de Contreras, así como las soluciones en las que insistirá durante toda su gestión. Ese mismo día informó haber recibido el sello de la Real Audiencia de Guadalajara, para lo cual se había realizado un acto con toda pompa ya que simbólicamente el sello le otorgaba el poder real a la Audiencia y con ello el nivel de Chancillería no subordinada a la de México.

Debido a que la Audiencia sólo contaba con dos oidores y dado que había sido nombrado presidente de la misma, Orozco insistirá constantemente sobre la consolidación de esta Real Audiencia como una manera incluso de incrementar la producción minera y los quintos reales. Sin embargo, otro tema lo ocupará especialmente, el de los indios en guerra. Después de señalar algunos problemas del reino como la falta de ministros para que predicaran la palabra de Dios, señalaba: "y los españoles han hecho gran daño a estos indios bárbaros que llaman chichimecas de donde ha nacido y nace la enemistad que con nosotros tienen, $y$ por esto nos han hecho $y$ hacen los daños que vM habrá oído". He destacado esta última frase porque deja en claro, desde su toma de posesión como presidente, que Orozco conocía la principal causa de la rebelión indígena. Y continúa:

Este año al principio del anduve más de sesenta leguas de tierra de guerra y ví y entendí de así lo que digo y los que más han damnificado han sido capitanes nombrados por los virreyes y Audiencia de México, y los mismos yo siendo oidor [...] con mis compañeros entiendo ahora [por] lo que [se] hicieron muy ricos [...], porque habían servido bien según ellos decían y lo peor es que les dábamos crédito y así entiendo nos engañaban como a hombres que no veíamos, y para que haya enmienda de este daño me parece que vM debe someter esta guerra y pacificación a persona de confianza que lo vea y ande en ella por su persona pagándoselo muy bien y si vs fuere servido someterlo a esta real Audiencia sea con que se de comisión para gastar de la real caja alguna cuantía y sin esto no habrá remedio. ${ }^{38}$

La causa de la guerra entonces era muy clara, dado que él mismo lo había visto y entendido personalmente en su experiencia como visitador: los capitanes enviados por el virrey que, además de hacerse ricos a costa de la esclavitud de los indios, engañaban a los oidores de la Audiencia de México, incluido él mismo, como lo confiesa, porque "no veíamos".

38 "Carta del doctor [Jerónimo de] Orozco, presidente de la Audiencia de Guadalajara", 22 de diciembre de 1572, AGI, Guadalajara, 5, r. 14, n. 28. Cursiva de vmGE. 
Otra de las cuestiones que habla de la gestión del doctor Orozco es que muy rápidamente logra hacer equipo con los dos oidores con los que cuenta la Audiencia, doctor Alarcón y licenciado Bobadilla, ya que de manera conjunta comenzarán a escribir al rey mostrando una política más integral que hasta ese momento no se había hecho. En carta del 24 de diciembre del mismo año de 1572, dos días después de la carta de Orozco, la Audiencia en conjunto informa que se recibió al nuevo presidente de la Audiencia, el doctor Orozco, "y nos ha parecido previsión tan acertada que en el favor de dios se tiene por cierto será muy bien gobernada esta tierra [...]". Comentan también que se recibió el sello real que vm envió a esta Real Audiencia y todas las autoridades y vecinos salieron a recibirlo "con la mayor pompa y oportunidad que se pudo [...]". Acusan recibo además de la real cédula del 18 de mayo de 1572 en el que vm "manda que esta Audiencia tenga la mesma autoridad y las cosas de justicia que la Audiencia Real de México y se cumplirá como vm lo manda". ${ }^{39}$ Así pues, estaban reconociendo el nuevo estatus de la Audiencia de Guadalajara, con "la mesma autoridad" que la de México, al recibir al presidente y el sello real que lo confirmaban.

En términos de gobierno y en cuestiones militares, sin embargo, seguían dependiendo del virrey, por lo que proponen sin poder ejecutarlo ellos mismos, un juicio de residencia a Francisco de Ibarra, gobernador de Nueva Vizcaya, por los excesos cometidos tanto en términos de trato a los indios como de fraudes a la hacienda real; informan además dado que la seguridad está a cargo del virrey como capitán general de este Reino "que por estar tan lejos y no tener las cosas presentes no solamente no se remedian antes se acrecientan los robos, salteamientos y muertes de mucha cantidad de indios y españoles [...] por lo que piden se ponga remedio y que esta Real Audiencia se encargue de ello". Es decir, proponen que también el gobierno militar pase a la Audiencia con el fin de tener una respuesta más cercana a los temas de este Reino de Nueva Galicia, por lo cual incluyen asimismo las propuestas de que la Casa de Moneda esté en Guadalajara, que se suspendan los trabajos en la salinas de la provincia de Purificación que tiene muchos costos, "sobre todo de la vida de muchos indios que trabajan en ellas [...]"; que la venta de azogue no se haga en estanco, que la plata no se cargue y se pese tantas veces entre Zacatecas,

39 "Carta de la Audiencia de Guadalajara”, 24 de diciembre de 1572, AGI, Guadalajara, 5, r. 14, n. 29. 
Guadalajara, México y Veracruz por la merma que va teniendo, perjudicando así a la hacienda real, en fin, que en las ceremonias religiosas, como ocurre en la ciudad de México, el agua bendita, el evangelio y la paz primero se le dé al presidente de la Audiencia antes que al obispo, y que en otras igualmente se le dé mejor lugar al presidente que al prelado, dado que "el obispo de este Reino se niega [...]" ${ }^{40}$

Esta primera carta de la Audiencia en conjunto era todo un programa de trabajo sobre el cual estarían insistiendo durante varios años, particularmente el doctor Orozco, quien mostró desde su llegada claridad en cuanto a los problemas del Reino y cómo enfrentarlos. De hecho existía cooperación con el virrey Enríquez, por ejemplo cuando la misma Audiencia de Guadalajara informó al rey que cerca de las minas de Zacatecas:

en donde dicen la Ciénega Grande se ha hecho un fuerte por mandato de don Martín Enríquez vuestro Visorey de la Nueva España y pueblo para soldados para dar la seguridad al camino y por el mes de octubre del año pasado cierta cantidad de los indios chichimecas se vinieron de paz y poblaron junto a la dicha Ciénega una legua de dicho fuerte donde están bastantes hombres con sus mujeres e hijos, hasta ahora han dado buenas muestras de amistad y si perseveran será cosa de grandísima importancia, por bien les mande dar vM de comer por algún tiempo y ponerle fraile franciscano que así van con ellos y entretanto que vм nos provea a esta Real Audiencia para la diligencia que convenga para conservar a los dichos y traer de más que fuere posible $[. . .]^{41}$

En este fuerte y pueblo de Ciénega Grande, cerca de Asientos de Ibarra en el actual estado de Aguascalientes, se observa la estrategia que sería finalmente la que años después predominaría en atención a los chichimecos, darles de comer y ponerles un fraile franciscano, lo cual correspondía proveer a la Audiencia de Guadalajara.

A partir de abril de 1573 a través de cédula real enviada al doctor Orozco directamente, se le autorizaba poblar la frontera "para que trate con algún hombre rico y haga asiento con él para fundar un pueblo en la frontera chichimeca $[\ldots] " .{ }^{42}$ Este mandato real no sólo le otorgaba atribuciones al

40 "Carta de la Audiencia de Guadalajara", 24 de diciembre de 1572, AGI, Guadalajara 5, r. 14, n. 29.

41 "Carta de la Audiencia de Guadalajara", 2 de marzo de 1573, AGI, Guadalajara, 5, r. 15, n. 32 .

42 "Poblamiento de la frontera chichimeca", 16 de abril de 1573, AGI, Guadalajara, 230, 1. 2, f. 1r; este mandato para continuar con el descubrimiento y el poblamiento sería ratifi- 
doctor Orozco como presidente de Audiencia de fundar pueblos en la frontera chichimeca, sino también de alguna manera anticipaba las Ordenanzas de descubrimiento, nueva población y pacificación firmadas por Felipe II el 13 de julio del mismo año de 1573. Habría que recordar que estas Ordenanzas fueron un parteaguas en la legislación indiana dentro de las reformas planeadas por Juan de Ovando, de hecho formaban parte del libro II del proyectado "Código ovandino". Y lo fueron por su permanencia, que se vio incorporada en la Recopilación de las leyes de 1680, pero también porque sintetizaba la experiencia y la doctrina, más allá de las diferentes cédulas a favor o en contra de los encomenderos, para reivindicar la centralidad de la Corona en el poblamiento y relación con la población indígena en especial. ${ }^{43}$ Sin embargo, las dificultades para llevarlas a la práctica se pueden observar desde la percepción del doctor Orozco, quien deja ver en esta carta dedicada al "Poblamiento de la frontera chichimeca" su conocimiento sobre las nuevas Ordenanzas.

Después de informar de la fundación de villas en años pasados (de Santa María de los Lagos "diez años a" (sic), y de Jerez "cuatro años a"), comenta las dificultades para poblar: "hemos mandado pregonar en este Reino que las personas que quisieren poblar otras dos villas en lugares convenientes de la frontera [...] que vм les haría mercedes de tierras de labor, estancias para ganados y otros aprovechamientos, y no hay quién ose poblar [...]". Si bien informa que ha estado en comunicación con el virrey Enríquez acerca de la seguridad de los caminos y poblaciones, comenta críticamente en especial que el gobierno y la política de pacificación y poblamiento sea llevada desde la ciudad de México:

la gente de esta ciudad [de Guadalajara] y distrito ha mostrado tanto sentimiento y tristeza que no lo podré significar teniendo por gran agravio, y dicen que la merced que vm les hacía en su casa por haber ganado y poblado esta tierra, ahora la han de ir a pedir ochenta leguas y algunos sirvientes de donde se les seguirá más costo y trabajo que el provecho que se les puede dar, y unos dicen que lo dejarán por no irlo a pedir y otros que saldrán del Reino a la Nueva España, donde vivirán quietos y sin guerra de indios, [...] si vм no manda a la persona que debiere de gobernar este Reino que asista en él ordinariamente se despoblará toda la mayor parte y digo

cado en las reales cédulas siguientes: AGI, Guadalajara, 230, 1. 1, f. 278r, del 6 de abril de 1574; AGI, Guadalajara, 230, 1. 2, f. 13r-14v, del 21 de abril de 1574.

${ }^{43}$ Diego-Fernández Sotelo, "Mito y realidad en las leyes de población”, 209-312. Incluye como apéndice las ordenanzas en facsimilar y paleografiadas. 
que es más necesario y conveniente que Resida en este Reino que no en México como hombre que lo he visto, y se lo uno y lo otro, y si no se hace así se menoscabarán y vendrán con gran disminución los quintos y diezmos de vM $[. ..] .^{44}$

El texto es relevante porque Orozco deja en claro que el gobierno de la frontera debe ser realizado desde la Audiencia de Guadalajara y no de la ciudad de México, cosa que será reafirmada en varias cartas de los oidores en el mismo mes de octubre de 1573: que la Audiencia de Guadalajara tenga "la misma autoridad y superioridad que la de México", por lo cual suplican que el presidente y oidores de México "no se entrometan [...] ni envíen semejantes jueces de comisión [...]”, y que el gobierno y la pacificación del Reino de la Nueva Galicia quede en manos de la Audiencia de Guadalajara. ${ }^{45}$ El doctor Orozco insistirá que mientras el gobierno y los asuntos de guerra los tenga el virrey, este reino se despoblará, por lo que solicita que se incremente el gasto para la seguridad de los caminos. ${ }^{46}$ Como luego lo señalará el doctor Orozco, el virrey le comisionó para fines de este año de 1573 también el gobierno militar, incluida la provincia de Nueva Vizcaya.

El doctor Orozco había reconocido la causa de la guerra y la inseguridad en que capitanes y soldados se pagaran esclavizando indios, de ahí que su propuesta fuera un mayor gasto para la guerra/paz con el fin de que las milicias fueran pagadas por la hacienda real y terminar así con la guerra. Orozco apuntaba hacia una consolidación de las instituciones de la Corona y no a la vieja tradición de que fueran intereses privados los que dictaran las políticas particularmente de guerra y de trato a los indios.

Finalmente en real cédula de 21 de abril de 1574 la Corona reconoció que el gobierno del reino le corresponde al presidente de la Audiencia de Guadalajara, si bien la Corona insistía que la guerra era asunto del virrey aunque aceptaba que éste la comisionara, como había ocurrido en la práctica, ya que el virrey comisionó al presidente Orozco para manejar los asuntos de guerra y de gobierno. En la misma cédula, el rey le ordena que amplíe el descubrimiento, población y pacificación de esas provincias, que la tierra

44 "Carta del doctor [Jerónimo de] Orozco, presidente de la Audiencia de Guadalajara", 10 de octubre de 1573, AGI, Guadalajara, 5, r. 15, n. 35.

45 "Carta de la Audiencia de Guadalajara", 12 de octubre de 1573, AGI, Guadalajara, 5, r. 15, n. 37; y "Carta de la Audiencia de Guadalajara", 25 de octubre de 1573, AGI, Guadalajara, 5 , r. 15, n. 38 .

46 "Carta del doctor [Jerónimo de] Orozco, presidente de la Audiencia de Guadalajara", marzo 20 de 1574, AGI, Guadalajara, 5, r. 16, n. 40. 
se labre y se cultive y se críen ganados, y que procure hacer justicia para que los naturales no reciban vejación. ${ }^{47}$

En octubre del mismo año de 1574 el doctor Orozco comentó acerca del gobierno y de la guerra que tenía también bajo su administración:

Los dos casos que vm reserva al virrey que son gobierno de guerra y gratificación de servicios conviene que todo ande junto y por ninguna vía haya división en el gobierno en cosa alguna, por inconvenientes que pueden seguir y los hemos visto en algunas cosas que el virrey ha proveído con buen celo por no lo ver ni tiene las cosas presentes como nosotros. Lo de la guerra yo lo tengo a mi cargo por comisión del virrey y se proveyó de un año a esta parte los capitanes y personas que han sido necesarias para asegurar los caminos y han sido de más efecto que los que había de veinte años antes $[\ldots] . .48$

De acuerdo con lo anterior, no sólo la administración de justicia, sino también de gobierno y de los asuntos de la guerra contra los chichimecas había quedado en manos del doctor Orozco. Se ha reconocido la importancia del virrey Enríquez a partir de la fundación de los siete presidios para la defensa de la frontera, incluso elogiados por el poeta González de Eslava; ${ }^{49}$ sin embargo, a partir de la revisión de esta correspondencia del doctor Orozco podemos conocer que el virrey Enríquez le “comisionó” también los asuntos de la guerra. De acuerdo con Parry, no obstante que el virrey Enríquez fue nombrado gobernador supremo de toda la Nueva España, "para 1574, la audiencia [de Guadalajara] había asumido la forma y autoridad que habría de mantener a través del periodo colonial, y que resultaba más o menos común, en ese entonces, a todas las audiencias en Indias". ${ }^{50}$ Para algunos autores, a partir de Enríquez el poder de los virreyes se fue consolidando; ${ }^{51}$ sin embargo, como lo han mostrado los estudios sobre las audiencias y en particular sobre la Nueva Galicia, el tema central sobre el

${ }^{47}$ AGI, Guadalajara, 230, 1. 2, f. 13r-14v, 21 de abril de 1574. La solicitud de incremento de salario será una constante en prácticamente todas las comunicaciones del doctor Orozco...

48 "Carta del doctor [Jerónimo de] Orozco, presidente de la Audiencia de Guadalajara", 11 de octubre de 1574, AGI, Guadalajara, 5, r. 16, n. 42. Texto resaltado por el autor.

${ }^{49}$ Powell, La guerra chichimeca, cap. viI "Presidios y poblados defensivos".

${ }^{50}$ Parry, La Audiencia de Nueva Galicia, 193. De hecho, como lo comenta el propio Orozco, recibió la "comisión" del virrey Enríquez de encargarse de las políticas de la guerra desde 1573, véase nota 52 previa.

${ }^{51}$ Lara Semboloni Capitani, La construcción de la autoridad virreinal en la Nueva España, 1535-1595 (México: El Colegio de México, 2014). 
Estado en Indias es en dónde residía la autoridad de la Monarquía compuesta dado el sistema pluricéntrico de gobierno. ${ }^{52}$

Sobre la Nueva Vizcaya, Orozco asumió que el rey también le había encomendado ese territorio, por lo que inmediatamente solicitó información a Francisco de Ibarra sobre dicha provincia; éste comentó que la falta de indios era el principal problema, y Orozco informó al rey que trataría también de favorecer el poblamiento en dicha provincia. Para ello, solicitó sacerdotes que hablaran la lengua de los indios del reino, que no era la mexicana, ante lo que se preguntaba qué tipo de cristiandad tenían los indios evangelizados sin que los sacerdotes hablaran sus lenguas. ${ }^{53}$

Orozco procuró limitar los excesos del capitán Ibarra, lo cual incluso es reconocido por Porras Muñoz después de reseñar brevemente el conflicto de Ibarra con el Obispado y la Audiencia de Guadalajara por territorios originalmente pertenecientes a la Audiencia. "Usurpado el territorio a la provincia de Nueva Galicia”, escribió Porras Muñoz, ya que el territorio en disputa pertenecía originalmente a la Nueva Galicia. ${ }^{54}$ Lamentablemente el trabajo de Porras no desarrolla la relación entre la Nueva Vizcaya y la Audiencia de Guadalajara, ya que el conflicto de jurisdicciones es una de las características de la Monarquía compuesta o de la Monarquía policéntrica, por lo que no fueron jurisdicciones estáticas.

Quizá un estudio más enfocado a este tema de conflicto de jurisdicciones es el de J. Lloyd Mecham, ya que no obstante mostrar la relevancia de Francisco de Ibarra para los intereses de la Corona, el autor reconoce también que Ibarra había excedido los límites jurisdiccionales que se le habían asignado al usurpar la autoridad de la Audiencia de Guadalajara, un tema que insisto no está suficientemente trabajado. ${ }^{55}$ De hecho, las arbitrariedades de los Ibarra, un ejemplo de las redes sociales familiares, retrasaron varios años el crecimiento de la minería en la región. ${ }^{56}$

52 Parry, La Audiencia de Nueva Galicia; Rafael Diego-Fernández Sotelo, "De las audiencias indianas", Los caminos de la justicia en México, 1810-1010 (México: Poder Judicial de la Federación, 2010), 3-30.

53 "Carta del doctor [Jerónimo de] Orozco, presidente de la Audiencia de Guadalajara", 1 de marzo de 1575, AGI, Guadalajara, 5, r. 17, n. 45.

${ }^{54}$ Guillermo Porras Muñoz, Iglesia y Estado en Nueva Vizcaya (1562-1821) (México: Universidad Nacional Autónoma de México, 1980), 16.

55 J. Lloyd Mecham, Francisco de Ibarra y la Nueva Vizcaya (Durango, México: Espacio Vacío Editorial, 1992), en especial cap. viI, “Ibarra versus la Audiencia de Guadalajara”, 261.

56 Jaime J. Lacueva Muñoz, "Marginalidad y marginación de la minería de la Nueva Vizcaya (1563-1631)”, Historias, n. 78 (2011): 39-72. 
En otra carta de Audiencia, firmada por el presidente y los oidores, además de informar sobre la plata enviada y algunos pleitos, comentarán que el virrey en materia de guerra se ha desatendido prácticamente, por lo que solicitan recursos para cuidar de los caminos. ${ }^{57}$ Orozco mismo reforzaría el hecho de que hacía casi dos años que el virrey se ha descargado de ser general de este reino "y me dio toda la comisión que de vm tiene de la guerra y yo lo he usado este tiempo [...]"; informa por ello que Francisco de Ibarra murió en agosto de 1575, por lo que mandó al capitán Hernando de Trejo para que gobierne la Nueva Vizcaya "hasta que vm nombre a otro". También recomendaría que los indios de las minas no pagaran el tributo por el trabajo que ya realizan, si bien comenta que los de los pueblos y huertas sí lo hacen; en el mismo sentido, señala que el cobro de la alcabala va a ser negativo para la economía del reino. ${ }^{58}$

En la práctica, Orozco había asumido el gobierno y el combate a los "indios salteadores" a partir del poblamiento y la evangelización, no "a fuego y a sangre" como generalmente se ha presentado desde la óptica del virrey Enríquez, para lo cual insistía en que sólo con más soldados pagados de la Real Hacienda se podrá pacificar esta tierra:

Yo hago y haré gran diligencia contra estos males [...] para lo cual he comandado a Poblar una villa quince leguas de Zacatecas que llaman La Asención en medio del Paso de los indios de guerra, en nombre de Vuestra Majestad se han repartido tierras y solares y aunque son pocos importa mucho para la defensa y el dejar daños en aquel camino y lo que más conviene en este Reino al servicio de dios y de vM está en gente pagada de ordinario y algunos Presidios en las partes que conviene y la persona que gobernare lo sea proveyendo vм dinero para ello y no basta someterlo al virrey sino lo ve por vista de ojos y lo que vm mandare gastar seguro se ganará con el cuatro tanto. ${ }^{59}$

La villa a la cual refiere que fundó es la villa de Aguascalientes, que al darle el nombre de Ascensión, "en el sitio y paso que dicen de Aguas calientes", como lo refiere el acta de fundación firmada por el doctor Orozco,

57 "Carta de la Audiencia de Guadalajara", 12 de marzo de 1575, AGI, Guadalajara, 5, r. 17, n. 46; AGI, Guadalajara, 5, r. 17, n. 49, 16 de septiembre de 1575.

58 "Carta del doctor [Jerónimo de] Orozco, presidente de la Audiencia de Guadalajara", 16 de septiembre de 1575, AGI, Guadalajara 5, r. 17, n. 48.

59 "Carta del doctor [Jerónimo de] Orozco, presidente de la Audiencia de Guadalajara", AGI, Guadalajara, 5, r. 18, n. 53. Negritas de VMGE. En el AGI está como "Carta de Audiencia”, sin embargo sólo está firmada por el doctor Orozco. 
se transformaría luego en la Alcaldía de Aguascalientes. ${ }^{60}$ De esta manera, la fundación de la villa de Aguascalientes, como la de León al año siguiente de 1576 por su hermano Juan Bautista Orozco como oidor de la Audiencia de México, sería el inicio de una política de pacificación al advertir la necesidad de fundar nuevas villas y pueblos junto al camino real. Esta política de poblamiento estuvo acompañada de cambios en la integración y la organización de las milicias.

En contra de la idea de que también esta región de la Nueva Galicia se vio igualmente afectada por las epidemias en el valle central de 1575-1576, los oidores y el presidente de la Audiencia de Guadalajara informan al rey: "del estado de este Reyno en el cual ha habido Salud y buenos temporales, paz y quietud en todo el año y las minas se celebran y benefician [...] se han descubierto en Zacatecas y en Jerez unas minas que se nombran de Las Cruces donde se ha comenzado a beneficiar y sacar plata [...]." ${ }^{61}$ Como en otros temas, el traslado de las problemáticas del valle central de la ciudad de México a otras regiones impide observar la dinámica propia de éstas, que es lo que se requiere para entender la Nueva Galicia. No fueron necesariamente las epidemias las causas del despoblamiento en este reino de Nueva Galicia, sino la presencia de soldados y capitanes que esclavizaban a los indios como paga, con la justificación de los sacerdotes. Por ello, Orozco en cada carta prácticamente insistiría en que se tengan nuevos capitanes y soldados, así como sacerdotes que entendieran la lengua de los indios. Para lo primero propuso que cada nuevo capitán tuviera cincuenta soldados y cien indios de paz pagados por la hacienda real, mil pesos a los capitanes y cuatrocientos a los soldados, para lo cual solicita autorización para sacar los salarios de la caja real y bajo el resguardo del capitán Rodrigo del Río, que para Orozco era la persona indicada para encabezar este nuevo proyecto. ${ }^{62}$

${ }^{60}$ Ignacio Fuentes, "Documentos antigüos relativos al estado de Aguascalientes”, Boletín de la Sociedad de Geografía y Estadística de la República Mexicana, v. III, (1871): 17-25. Presenta tanto el acta de fundación como el informe de la Subdelegación de 1794; el acta como la carta de Orozco dicen "villa de la Ascensión (que es de Jesucristo) en un paso y sitio que llaman de las Aguas calientes”; por cambios realizados en la transcripción del acta, quedaría como "villa de nuestra señora de la Asunción (que es de la virgen) de un fuerte de las Aguas calientes..." El tema de la alcaldía se da precisamente a principios del siglo XVII, como lo refiere la misma acta de fundación, transcrita a petición del alcalde mayor Juan de Monroy, de las villas de Aguascalientes y Lagos, y corregidor de Teocaltiche, en el año de 1611.

61 "Carta de la Audiencia de Guadalajara", 19 de octubre de 1576, AGI, Guadalajara 5, r. 18 , n. 60.

62 "Carta del doctor [Jerónimo de] Orozco, presidente de la Audiencia de Guadalajara", s. f., AGI, Guadalajara, 5, r. 19, n. 69, pero probablemente de octubre de 1576. 
Hacia el año de 1577 se informa de la visita a Zacatecas por parte del oidor de la Audiencia de Guadalajara Santiago del Riego, sobre la cual se conoce su informe. Tenía que ver con las denuncias de frecuentes fraudes en el beneficio de la plata, además de robos y alteraciones del orden público. El historiador Antonio García-Abásolo, quien ha estudiado esta visita, comenta que posiblemente fue realizada a instancias del virrey Enríquez; ${ }^{63}$ sin embargo, era parte de los acuerdos de la propia Audiencia de Guadalajara de visitar más frecuentemente el real de minas. De hecho, el doctor Orozco informó sobre la buena relación de amistad que tiene con los oidores, entre ellos Santiago del Riego, porque además "son de los mejores jueces que he conocido", por lo que se atreve a plantear que la Audiencia pudiera tener más atribuciones sobre los oficiales y el sistema de cuentas. ${ }^{64}$ De ahí que la visita a las minas de Zacatecas, además de las de Fresnillo, Sombrerete y Nieves por Del Riego fuera planteada por la propia Audiencia de Guadalajara. ${ }^{65}$

Además de atender los frecuentes desórdenes propiciados por las borracheras, 70 indios habían muerto por los frecuentes pleitos en Zacatecas, el oidor Del Riego se focalizó en los robos y fraudes ocurridos en las minas, básicamente por las "pepenas" de negros e indios que obtenían para su propio peculio, a veces a deshoras, y que beneficiaban en hornillos no autorizados y comerciaban fuera de los circuitos oficiales. Todo ello en perjuicio de mineros y comerciantes que pagaban el quinto real, pero permitido por los oficiales. ${ }^{66}$ De ahí que Del Riego tomó residencia al alcalde mayor y a los oficiales de Zacatecas, y al no conocer éstos las ordenanzas de Mendiola, que había redactado en 1567, sino las De la Marcha de más de veinte y siete años atrás, decidiera redactar unas nuevas que serían el resultado de su visita.

Ante la propuesta del fiscal de la Audiencia de México Alonso Martínez, tema que resurgiría de vez en vez incluso en el siglo xviI, de que la Audiencia de Guadalajara se trasladara a Zacatecas, tanto el doctor Orozco como el oidor Del Riego se opusieron fundamentalmente por la buena ubicación de Guadalajara para mantener asentados a los indios pacificados, pero sobre

${ }^{63}$ García-Abásolo González, "Resultados de una visita”, 6.

64 "Carta del doctor [Jerónimo de] Orozco, presidente de la Audiencia de Guadalajara", 6 de marzo de 1577, AGI, Guadalajara, 6, r. 1, n. 2.

65 "Carta de la Audiencia de Guadalajara", 7 de marzo de 1577, AGI, Guadalajara, 6, r. 1 , n. 6 .

${ }^{66}$ García-Abásolo González, "Resultados de una visita”, 12. 
todo, escribió el doctor Orozco, "no conviene la mudanza porque los indios salteadores que hay en este Reino a lo que se entiende no son muy unidos y éstos andan divididos en los caminos [...] y en los pasos peligrosos, y éstos podrían ser resistidos y evitados sus daños con poner vm por los caminos de Nueva España y de este Reino algunos presidios de soldados [...]". ${ }^{67}$ En cuanto a la propuesta de Del Riego sobre el combate a los indios chichimecas, prácticamente seguiría lo comentado previamente por el doctor Orozco: contratar capitanes y soldados, pagados por la hacienda real, para proteger los caminos y los centros mineros. Este cambio se dio paulatinamente, si bien persistirían las prácticas de que intereses privados (o "mercenarios") intervinieran en la organización militar, aunque con el límite de no esclavizar más a los indígenas. ${ }^{68}$

De acuerdo con Del Riego, aclarando la causa de las rebeliones indígenas:

La mayor lástima es que estos daños [se refería a los causados por los indios chichimecas] han tenido principio de nosotros mismos. Diciendo la verdad mera y pura, han nacido de entradas exorbitantes que han hecho capitanes, no sé por cuya orden, que atendiendo a sus propios intereses, dejando los enemigos que tenían a la puerta de casa, han entrado cien y doscientas leguas y sacado indios en grandísima cantidad que jamás infestaron ni supieron sino atender a sus pesquerías y míseras labranzas [...] y precisamente hacen esto con los que salen a recibirlos con regalos, y les ponen hierros y llevan a vender por esclavos. ${ }^{69}$

Este mecanismo, que propició la guerra chichimeca muy bien descrito por Del Riego, también había sido planteado por Orozco desde 1572 como ya lo he comentado previamente, y está conectado con el Memorial de Luis Sánchez y el informe de Guillermo de Santa María, analizados inicialmente en este trabajo, lo que hace suponer que ya se tenía un buen diagnóstico de la guerra, además de una excelente colaboración entre Del Riego y el doctor Orozco. ${ }^{70} \mathrm{El}$ doctor Orozco llegó a comentar que con las nuevas ordenanzas

67 "Carta del doctor [Jerónimo de] Orozco, presidente de la Audiencia de Guadalajara", 2 de diciembre de 1577, AGI, Guadalajara, 6, r. 1, n. 14.

${ }^{68}$ García-Abásolo, Resultados de una visita, 18.

${ }^{69}$ García-Abásolo, Resultados de una visita, 19-20.

${ }^{70}$ García-Abásolo González, "Resultados de una visita”, 23. El autor considera que no había buena relación entre Del Riego y Orozco, porque tiene la idea de que este último era de alguna manera cómplice de los defraudadores. Tanto Santiago del Riego como Santiago Vera, oidores de la Audiencia de Guadalajara, ya con nuevos nombramientos para la Audiencia de México, comentan sobre "el mucho cuidado y vigilancia" que tiene el doctor Orozco 
de Del Riego "se espera aumentar los quintos y los diezmos [...]", apoyando el trabajo realizado por el oidor con quien trabajaría hasta el año de $1579 .{ }^{71}$

Quizá lo que habría que comenzar a aceptar, como lo he tratado de mostrar en este trabajo, es que bajo la presidencia del doctor Jerónimo de Orozco la Audiencia de Guadalajara se encargó no sólo de la administración de justicia como chancillería real sino también del gobierno y la administración de la guerra para alcanzar la paz, que era uno de los propósitos de las reformas ovandinas a través de las Ordenanzas de poblamiento. De hecho tanto el virrey Enríquez, en una carta dirigida al rey solicitando un apoyo extraordinario, como la respuesta del monarca aceptaron la propuesta de Orozco, en el sentido de que el recurso para los soldados saliera de la Real Hacienda. ${ }^{72}$ Desde luego la guerra continuaría por muchos años más, así como la intervención de los intereses particulares en las milicias, pero la política de poblamiento y pacificación en la región, más que la de conquista a fuego y a sangre, se iniciaría con las reformas propuestas por Juan de Ovando y ejecutadas en Nueva Galicia por la Audiencia, bajo la conducción del doctor Orozco, a quien poco se le ha reconocido en la historiografía de la época.

El 19 de septiembre de 1580 se le envió una real provisión al doctor Orozco como presidente de la Audiencia de Quito. ${ }^{73}$ Es decir, se le trasladaba a otra audiencia menor, pero hasta el último momento insistiría en su estrategia de que el pago de los capitanes y soldados fuera de la Real Hacienda, sobre todo ante la creciente rebeldía de los indios chichimecos. ${ }^{74}$ El día

sobre el combate a los indios salteadores, "Carta de la Audiencia de Guadalajara”, 26 de noviembre de 1578, AGI, Guadalajara, 6, r. 2, n. 19.

71 "Carta del doctor [Jerónimo de] Orozco, presidente de la Audiencia de Guadalajara", 2 de diciembre de 1577, AGI, Guadalajara, 6, r. 1, n. 14. Los oidores Santiago de Vera y Santiago del Riego informaron del intento de asesinato al doctor Orozco por parte de Francisco Ortiz, canciller de la Audiencia, mostrando con ello legítima preocupación por el presidente: "Carta de la Audiencia de Guadalajara", 18 de junio de 1577, AGI, Guadalajara, 6, r. 1, n. 9. Orozco y Del Riego mantuvieron correspondencia conjunta con el rey; la última carta firmada por ambos es: "Carta de la Audiencia de Guadalajara", 26 de agosto de 1579, AGI, Guadalajara, 6, r. 3, n. 32 .

72 "Carta del virrey Martín Enríquez de Almansa”, 8 de abril de 1579, AGI, México, 20, n. 17; en este mismo documento está también la respuesta del rey en el sentido de autorizar los gastos necesarios para la seguridad de los caminos a las minas zacatecanas.

73 AGI, Quito, 211, 1. 2, f. 55r-56v, 19 de septiembre de 1580. Hacia el 15 de diciembre se nombra al doctor Hernando de Robles, oidor que era de la Audiencia de México, nuevo presidente de la Audiencia de Guadalajara: "Carta de la Audiencia de Guadalajara", AGI, Guadalajara, 230, 1. 1, f. 370r-371r.

74 "Carta del doctor [Jerónimo de] Orozco, presidente de la Audiencia de Guadalajara", 28 de septiembre de 1580, AGI, Guadalajara, 6, r. 4, n. 40. 
de navidad del mismo año de 1580 los oidores Antonio Alcalde y Francisco Tello informan al rey de la muerte del doctor Orozco el 6 de diciembre, insistiendo en la "mucha limpieza y diligencia" de un honesto funcionario:

habiendo llegado al fuerte que llaman del Cuicillo a nueve leguas de Zacatecas fue dios servido del llevarle para sí en seis del presente mes de diciembre con mucho sentimiento y dolor de todo el reino de quien era muy amado y querido por sus muchas y buenas partes y acertada orden en el gobierno y habiendo servido a vM con mucha limpieza y diligencia en estas partes más de veinte y tres años las riquezas y bienes que deja a su mujer y diez hijos de los cuales son la mitad hijas fue siete mil pesos de deudas y ningunos bienes que basten para la paga de la menor parte de cual es lástima para conque se puedan sustentar porque no les queda otro ningún remedio ni recurso sino es la merced vm mandara hacerles [...]. ${ }^{75}$

\section{Reflexiones finales}

Dentro del proceso de conformación de la Monarquía compuesta castellana a partir del siglo XvI, se iniciaron bajo el reinado de Felipe II una serie de reformas encabezadas por Juan de Ovando, quien sería visitador y presidente del Consejo de Indias hasta su muerte en 1575. La historiografía tradicionalmente ha atribuido al virrey Enríquez la instrumentación de estas reformas y particularmente la política de la guerra "a sangre y fuego" contra los indios rebeldes de la Nueva Galicia. Sin embargo, analizando las cartas e informaciones del doctor Orozco, presidente de la Audiencia de Guadalajara a partir de 1572 y gobernador con las atribuciones militares desde 1573, se pudo encontrar una visión clara sobre las causas de la guerra y cómo remediarla, ya existente en varios tratadistas como Guillermo de Santa María, por lo que su punto de vista es fundamental para comprender la instrumentación de las reformas impulsadas por Felipe II en la Nueva Galicia.

Más aún, la propuesta de profesionalizar a las milicias y de limitar o cambiar la vieja estrategia de capitanes y soldados financiados de manera privada, lo cual propiciaba la esclavitud de indios incluso de paz, la encontramos tempranamente en las políticas desarrolladas por el doctor Jerónimo de Orozco desde la Audiencia de Guadalajara. Ello sería el inicio de lo que se ha dado en llamar "revolución militar" en uno de los reinos de frontera,

75 "Carta de la Audiencia de Guadalajara”, 24 de diciembre de 1580, AGI, Guadalajara 6, r. 4 , n. 41. 
como lo fue la Nueva Galicia, y que lo ejemplificaría muy bien el capitán mestizo Miguel Caldera, quien fuera soldado originalmente de Jerónimo de Orozco, personaje determinante de la pacificación en dicho reino bajo las políticas del virrey Villamanrique. ${ }^{76}$

\section{Fuentes CitadAS}

\section{Recurso electrónico}

Portal de Archivos Españoles (Pares), Archivo General de Indias, Cartas de Audiencia, Audiencia de Guadalajara, México y Quito, http://pares.mcu.es/ParesBusquedas20/catalogo/find?nm=\&texto=cartas + de+audiencia + guadalajara .

\section{Archivos internacionales}

Archivo General de Indias (AGI), Contratación, Guadalajara, México, Quito.

\section{Archivos nacionales}

Archivo de la Real Audiencia de Guadalajara, Biblioteca del Estado de Jalisco "Juan José Arreola, Universidad de Guadalajara, Guadalajara, Jalisco.

Archivo Histórico del Estado de Aguascalientes.

\section{Bibliografía}

Álvarez, Salvador. "Conquista y encomienda en la Nueva Galicia durante la primera mitad del siglo XvI: 'Bárbaros' y 'civilizados' en las fronteras americanas." Relaciones. Estudios de historia y sociedad, v. XxIX, n. 116 (2008): 135-188.

Álvarez, Salvador. "La guerra chichimeca." En Historia del Reino de la Nueva Galicia. Edición de Thomas Calvo y Aristarco Regalado Pinedo, 165-159. Guadalajara, Jalisco: Universidad de Guadalajara, 2016.

${ }^{76}$ Powell, Capitán mestizo: Miguel Caldera y la frontera norteña; Juan Carlos Ruiz Guadalajara, "Capitán Miguel Caldera y la frontera Chichimeca: entre el mestizo historiográfico y el soldado del rey”, Revista de Indias, v. Lxx, n. 248 (2010): 23-58. Paradójicamente, las políticas de pacificación a partir de 1585 estarían impulsadas desde el virreinato, no desde la Audiencia de Guadalajara, especialmente con el virrey Villamanrique, quien enfrentó en la "pequeña guerra" a los oidores de Guadalajara. 
André, Sylvain. "El momento ovandino. De la empresa de saber a la fábrica de la acción." E-Spania. Revue interdisciplinaire d'études hispaniques médievales et modernes (en línea), n. 33 (2019), https://doi.org/https://doi.org/10.4000/espania.30715.

Assadourian, Carlos Sempat. Zacatecas. Conquista y transformación de la frontera en el siglo XVI. Minas de plata, guerra y evangelización. México: El Colegio de México, 2008.

Barrientos Grandon, Javier. "Juan de Ovando." En Diccionario biográfico español. V. xxxix, 372-378. Madrid: Real Academia de la Historia, 2012.

Becerra Jiménez, Celina B. "En servicio del Rey y de Dios: institucionalización en el siglo xvi." En Historia del Reino de la Nueva Galicia. Edición de Thomas Calvo y Aristarco Regalado Pinedo, 263-315. Guadalajara, Jalisco: Universidad de Guadalajara, 2016.

Carrillo Cázares, Alberto (ed. crítica, est. introd. y paleog.). El debate sobre la guerra chichimeca, 1531-1585. 2 v. Zamora: El Colegio de Michoacán; San Luis Potosí: El Colegio de San Luis, 2000.

Diego-Fernández Sotelo, Rafael. “De las reales audiencias indianas.” En Los caminos de la justicia en México, 1810-2010, 3-30. México: Poder Judicial de la Federación, 2010.

Diego-Fernández Sotelo, Rafael. "El aparato de gobierno y justicia indiano a partir de las reformas ovandinas." Allpanchis, v. xxxix, n. 71 (2008): 13-44.

Diego-Fernández Sotelo, Rafael. La primigenia Audiencia de la Nueva Galicia, 15481572. Zamora: El Colegio de Michoacán; Guadalajara: Instituto Cultural Ignacio Dávila Garibi, 1994.

Diego-Fernández Sotelo, Rafael. "La visita al Consejo de Indias de Juan de Ovando y la Nueva España.” Revista Chilena de Historia del Derecho, n. 22 (2010): 445-457.

Diego-Fernández Sotelo, Rafael. "Mito y realidad en las leyes de población de Indias.” En Recopilación de leyes de los reynos de las Indias/Estudios histórico-jurídicos, 209-332. México: Miguel Ángel Porrúa, 1987.

Elliott, John H. "Una Europa de monarquías compuestas." En España, Europa y el mundo de ultramar (1500-1800), 29-54. Madrid: Taurus Historia, 2009.

Espino López, Antonio. "Las Indias y la tratadística militar hispana de los siglos XVI y xviI." Anuario de Estudios Americanos, v. 57, n. 1 (2000): 295-320.

Foin, Charles. "Un pacificateur du nord du Mexique: Rodrigo de Río de Losa." Mélanges de la Casa de Velázquez, v. 14 (1978): 173-214.

Fuentes, Ignacio. "Documentos antigüos relativos al estado de Aguascalientes." Boletín de la Sociedad de Geografía y Estadística de la República Mexicana, v. III (1871): 17-25. 
García-Abásolo, Antonio F., coord. Historia de las Américas, II. México en el siglo XVI. 4 v. Editado por Luis Navarro García, 49-67. Madrid: Alhambra-Longman; Sevilla: Universidad de Sevilla, 1992.

García-Abásolo González, Antonio Francisco. "Resultados de una visita a Nueva Galicia." Anuario de Estudios Americanos, n. 36 (1979): 3-39.

Garriga, Carlos. "Orden jurídico y poder político en el Antiguo Régimen.” Istor. Revista de Historia Internacional, v. Iv, n. 16 (2004): 2-21.

Gil Pujol, Xavier. Tiempo de política. Perspectivas historiográficas sobre la Europa moderna. 1a. reimp. Barcelona: Universitat de Barcelona, 2010.

Goicovich, Francis. "Dinámica de la confrontación hispano-indígena en el Reino de Nueva Galicia y regiones adyacentes, siglo XvI." Revista de Indias, v. LXXIX, n. 275 (2019): 9-49.

Hespanha, Antonio Manuel. "Una nueva historia política e institucional." Revista Mexicana de Ciencias Políticas y Sociales, v. 41, n. 166 (1996): 9-45.

Iguíniz, Juan B. Los gobernantes de Nueva Galicia. Datos y documentos para sus biografías. Guadalajara, Jalisco: Gobierno de Jalisco, 1981.

Lacueva Muñoz, Jaime J. "Marginalidad y marginación de la minería de la Nueva Vizcaya (1563-1631).” Historias, n. 78 (2011): 39-72.

León-Portilla, Miguel. Francisco Tenamaztle, primer guerrillero de América, defensor de los derechos humanos. México: Diana, 2005.

Marchena Fernández, Juan, y Ramón Romero Cabot. "El origen de la hueste y de la institución militar indianas en la guerra de Granada." En Andalucía y América en el siglo XVI. Actas de las II Jornadas de Andalucía y América, 91-112. Huelva: Universidad de Santa María de la Rábida, 1982.

Mazín, Óscar, y José Javier Ruiz Ibáñez, eds. Las Indias Occidentales. Procesos de incorporación territorial a las monarquías ibéricas. México: El Colegio de México, 2012.

Mecham, J. Lloyd. Francisco de Ibarra y la Nueva Vizcaya. Durango, México: Espacio Vacío Editorial, 1992.

Parker, Geoffrey. Felipe II. La biografía definitiva. Ebook. Barcelona: Planeta, 2018.

Parker, Geoffrey. La Revolución militar. Las innovaciones militares y el apogeo de Occidente, 1500-1800. Barcelona: Crítica, 1990.

Parker, Geoffrey. “The ‘Military Revolution', 1560-1660-a Myth?” En The Military Revolution Debate: Readings on the Military Transformation of Early Modern Europe. Ebook. [New York]: Routlege, 2018, https://doi.org/10.4324/9780429496264.

Parry, John H. La audiencia de Nueva Galicia en el siglo XvI. Estudio sobre el gobierno colonial español. Edición de Rafael Diego-Fernández Sotelo. Zamora: El Colegio de Michoacán; México: Fideicomiso Teixidor, 1993.

Pietschmann, Horst. "Actores locales y poder central. La herencia colonial y el caso de México.” Relaciones. Estudios de historia y sociedad, v. XIX, n. 73 (1998): 52-83. 
Pietschmann, Horst. El Estado y su evolución al principio de la colonización española de América. México: Fondo de Cultura Económica, 1989.

Porras Muñoz, Diego. "Diego de Ibarra y la Nueva España.” Estudios de Historia Novohispana, n. 2 (1968): 48-78.

Porras Muñoz, Guillermo. Iglesia y Estado en Nueva Vizcaya (1562-1821). México: Universidad Nacional Autónoma de México, 1980.

Powell, Philip W. Capitán mestizo: Miguel Caldera y la frontera norteña. La pacificación de los chichimecas (1548-1597). 1a. reimp. México: Fondo de Cultura Económica, 1997.

Powell, Philip Wayne. La guerra chichimeca (1550-1600). Lecturas Mexicanas. México: Fondo de Cultura Económica, 1984.

Powell, Philip Wayne. "Portrait of an American Viceroy: Martín Enríquez (15681583)." The Americas, v. 14, n. 1 (1957): 1-24.

Rivero Rodríguez, Manuel. La edad de oro de los virreyes. Madrid: Akal, 2011.

Ruiz Guadalajara, Juan Carlos. "Capitán Miguel Caldera y la frontera chichimeca: entre el mestizo historiográfico y el soldado del rey.” Revista de Indias, v. Lxx, n. 248 (2010): 23-58.

Sánchez, Luis. "Memorial que dio el bachiller Luis Sánchez, residente en Chillaron de Pareja, al presidente Espinosa, en Madrid á 26 de Agosto de 1566.” En Colección de documentos inéditos, relativos al descubrimiento, conquista y organización de las antiguas posesiones españolas de América y Oceanía, sacados de los archivos del reino, y muy especialmente del de las Indias, por D. Luis Torres de Mendoza. Tomo XI, 163-170. Madrid: Imprenta de J. M. Pérez, 1869.

Santa María, Guillermo de. Guerra de los chichimecas (México 1570-Zirosto 1580). Edición de Alberto Carrillo Cázares. Zamora: El Colegio de Michoacán; Guadalajara, Jalisco: Universidad de Guadalajara; San Luis Potosí: El Colegio de San Luis, 1999. Thompson, Irving A. Anthony. "Milicia, sociedad y Estado en la España moderna." En La guerra en la historia. Edición de Ángel Vaca Lorenzo, 115-134. Salamanca, España: Universidad de Salamanca, 1999.

Velásquez Arango, Juan José. "Guerra, estado y revolución militar en la América española durante los siglos xvi y XviI.” Historia y Memoria, n. 16 (2018): 23-52.

Yun Casalilla, Bartolomé. "El imperio español entre la monarquía compuesta y el colonialismo mercantil”. En Historia global, historia transnacional e historia de los imperios. El Atlántico, América y Europa (siglos XVI-XVIII), 229-270. Zaragoza: Institución Fernando el Católico, 2019.

Zavala, Silvio A. Las instituciones jurídicas en la conquista de América. Madrid: Centro de Estudios Históricos, Sección Hispanoamericana, 1935.

Zavala, Silvio A. "Los intereses particulares en la conquista de la Nueva España (Estudio histórico-jurídico).” Tesis de doctorado en Derecho, Universidad Central de Madrid, 1933. 


\section{SOBRE EL AUTOR}

El autor es originario de Aguascalientes, estudió la licenciatura de Sociología en la UNAM (se graduó con mención honorífica), la maestría en Historia de América en el Instituto de Investigaciones Dr. José María Luis Mora (con mención honorífica), y el doctorado en Estudios Latinoamericanos en la Universidad de Tulane. En 2017 recibió mención honorífica del Comité Mexicano de Ciencias Históricas por artículo publicado en la categoría de Historia del Arte y del Patrimonio, y es miembro del Sistema Nacional de Investigadores, nivel I. Actualmente es profesor-investigador de la Universidad Autónoma de Aguascalientes, México. Sus líneas de investigación son historiografía contemporánea, así como familia y mestizaje en Nueva España. Entre sus publicaciones recientes destacan Dejando los restos del naufragio. Fragmentos para una historia cultural (Aguascalientes: Universidad Autónoma de Aguascalientes, 2016); Resignificar el mestizaje Tierra Adentro. Aguascalientes, Nueva Galicia, siglos XVII y XVIII (Aguascalientes: Universidad Autónoma de Aguascalientes; San Luis Potosí: El Colegio de San Luis, 2018); Valiéndome del derecho natural. La lucha de mujeres esclavas por sus derechos en Nueva Galicia (Aguascalientes: Universidad Autónoma de Aguascalientes, 2020). 